We thank M Vaquero for dissecting the coronary arteries; J C Borondo for pathologic evaluations; R Llombart for collecting anatomical specimens; E Casals for supervising biochemical analyses; D Zambon for support in statistical analysis; M Guevara and $\mathrm{C}$ Bauchet for lipoprotein and thiocyanate determinations; Instituto Anatómico Forense, Barcelona; and J Marrugat for reviewing the manuscript.

Contributors: $\mathrm{AB}, \mathrm{ER}$, and $\mathrm{OGV}$ conceived and designed the study. OGV and XF processed the histological samples of the coronary arteries and scored the lesions. MV and JCL processed and interpreted measurements of fatty acids in adipose tissue. $\mathrm{AG}, \mathrm{XF}$, and ER analysed and interpreted the data. AB and ER drafted and revised the paper. AB and ER are guarantors. See bmj.com for details of the Estudio Forense de Aterosclerosis Preclínica study group.

Funding: Spanish Health Ministry, FIS 96/2006.

Competing interests: None declared.

Ethical approval: Not required.
1 McGill HC Jr, McMahan CA, Herderick EE, Malcom GT, Tracy RE, Strong JP. Origin of atherosclerosis in childhood and adolescence. Am Clin Nutr 2000;72(suppl):1307-15S.

2 Tunstall-Pedoe H, Vanuzzo D, Hobbs M, Mahonen M, Cepaitis Z, Kuulasmaa K, et al. Estimation of contribution of changes in coronary care to improving survival, event rates, and coronary heart disease mortality across the WHO MONICA Project populations. Lancet 2000;355:688700.

3 Villar Álvarez F, Banegas Banegas JR, Donado Campos JM, Rodríguez Artalejo F. Las enfermedades cardiovasculares y sus factores de riesgo en España: hechos y cifras. Informe SEA 2003 [Cardiovascular diseases and their risk factors in Spain: facts and figures: a report from the Spanish Atherosclerosis Society 2003]. Madrid: Ergon, 2003. (In Spanish.)

4 Law M, Wald N. Why heart disease mortality is low in France: the time lag explanation. BMJ 1999;318:1471-80.

5 Marrugat J, Masiá R, Elosua R, Covas MI. Cardiovascular protective factors: can they explain for differences in mortality and morbidity between the Mediterranean and the Anglo-Saxon population? Cardiovaso Risk Factors 1998;9:196-204.

(Accepted 15 July 2003)

\title{
Contribution of timetabled physical education to total physical activity in primary school children: cross sectional study
}

Katie M Mallam, Brad S Metcalf, Joanne Kirkby, Linda D Voss, Terence J Wilkin

Department of Endocrinology and Metabolism, Peninsula Medical School, Derriford Hospital, Plymouth PL6 8DH

Katie M Mallam paediatric research fellow

Brad S Metcalf statistician

Joanne Kirkby assistant statistician Linda D Voss senior research fellow Terence J Wilkin professor of medicine

Correspondence to: T J Wilkin

terence.wilkin@ phnt.swest.nhs.uk

BMJ 2003;327:592-3
A recent survey of children at primary schools in England found a marked decline in timetabled physical education between 1994 and 1999. ${ }^{1}$ Sport England expressed concern about the impact of competing priorities, such as numeracy and literacy, on curricular physical education and concluded that children from poorer backgrounds would be worst affected. We used accelerometers to measure the impact of timetabled physical education at school on overall physical activity in children.

\section{Participants, methods, and results}

We monitored physical activity during waking hours for seven days using accelerometers (Manufacturing Technology, Fort Walton Beach, $\mathrm{FL}^{2}$ ) in 215 children (120 boys and 95 girls aged 7.0-10.5 (mean 9.0) years) from three schools with different sporting facilities and opportunity for physical education in the curriculum. School 1, a private preparatory school with some boarding pupils, had extensive facilities and 9.0 hours a week of physical education in the curriculum. School 2, a village school awarded Activemark gold status for its focus on physical activity, offered 2.2 hours of timetabled physical education a week. School 3, an inner city school with limited sporting provision, offered 1.8 hours of physical education a week.

The accelerometer electronically measures clock time, duration and intensity of movement, and is highly reproducible. ${ }^{3}$ Compliance was defined as complete recordings over at least four school days and one day of the weekend. Parents completed questionnaires assessing their income on a six point scale. We used analysis of variance to compare means between schools. Least significant difference $\mathrm{P}$ values are quoted.

A total of $74 \%$ ( 85 boys and 74 girls) complied with their accelerometers; compliant and non-compliant children did not differ in body mass index $\left(\mathrm{kg} / \mathrm{m}^{2}\right)$ or household income. As expected, pupils in School 1 recorded the most activity in school time but this was barely twice that of pupils in Schools 2 or 3 (both $\mathrm{P}<0.001)$ despite timetabling more than four times the amount of physical education (figure). Surprisingly, total physical activity between schools was similar because children in Schools 2 and 3 did correspondingly more activity out of school than children at
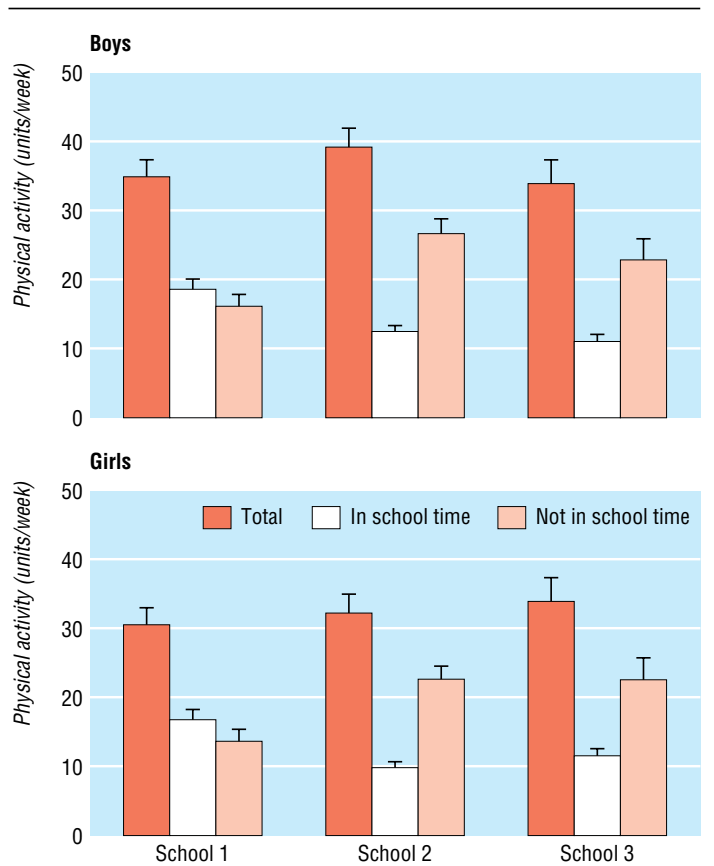

Mean physical activity done by children at three primary schools (error bars show upper limit of 95\% confidence interval) 
School 1 (both $\mathrm{P}<0.001$ ). Among the boys, total activity was higher in School 2 than in School 1 and School 3 (both $\mathrm{P}=0.02$ ) with mean (standard deviation) units of activity a week of 39.1 (6.8), 34.7 (7.7), and 33.8 (7.8).

In general, girls did less physical activity a week than boys (32.7 (6.8) v 35.9 (7.7) units; $\mathrm{P}=0.007)$, but their patterns according to school were the same. Mean household incomes were 5.5, 4.3, and 2.7 units in the three schools (all $\mathrm{P}<0.001$ ).

\section{Comment}

The total amount of physical activity done by primary school children does not depend on how much physical education is timetabled at school because children compensate out of school. This is unexpected, but encouraging, because the amount of timetabled physical education offered in School 1 is unlikely to be bettered elsewhere, and children from School 3 (the poorest) were not adversely affected. Less encouraging is that girls do significantly less physical activity than boys yet are known to have higher insulin resistance and triglyceride levels. ${ }^{4}$ It may be relevant that more girls than boys develop type 2 diabetes in childhood.

We cannot comment on whether physical activity among primary school children has declined, but we found no evidence that children from poorer backgrounds are adversely affected-they recorded the same overall physical activity as the most privileged children. The survey by Sport England was conducted by questionnaire, and its conclusions differ from ours. ${ }^{1}$ We will publish data on the intensity of physical activity and metabolic health of the children elsewhere. Our findings need confirmation but give cause for reflection on methods of collecting activity data, the provision of physical education in school, and the competing demands of the school curriculum.

Our study is part of EarlyBird, a 12 year programme investigating childhood factors which lead to diabetes in later life. We thank Claire Snow for collecting and inputting the data and Jonathan Williams for inputting the data.

Contributors: TJW and LDV conceived the study. KMM, TJW, and LDV designed the study. KMM collected and managed the data. KMM, BSM, and JK analysed the data. All authors interpreted the data and wrote the paper. TJW is the guarantor. Funding: South and Southwest NHS Executive Research and Development.

Competing interests: None declared.

Ethical approval: Plymouth local research ethics committee of the South and West Devon Health Authority.

1 Rowe N, Champion R. Young people and sport national survey 1999. London: Sport England, 2000.

2 Ekelund U, Sjostrom M, Yngve A, Poortvliet E, Nilsson A, Froberg K, et al. Physical activity assessed by activity monitor and doubly labelled water in children. Med Sci Sports Exerc 2001;33:275-81.

3 Metcalf BS, Curnow JS, Evans C, Voss LD, Wilkin TJ. Technical reliability of the CSA activity monitor (EarlyBird 8). Med Sci Sports Exerc 2002;34:1533-7.

4 Murphy MJ, Mallam KM, Voss LD, Jeffery AN, Kirkby J, Wilkin TJ. Girls at five are intrinsically more insulin resistant than boys: the programming hypotheses revisited (EarlyBird 6). Pediatrics. In press.

(Accepted 17 April 2003)

\title{
Severe traffic injuries to children, Trent, 1992-7: time trend analysis
}

\author{
Carol Coupland, Julia Hippisley-Cox, Denise Kendrick, Lindsay Groom, Elizabeth Cross, \\ Boki Savelyich
}

Unintentional injury is the leading cause of death in children aged 1 to 15, and two thirds of fatal injuries in schoolchildren result from road traffic crashes. ${ }^{1}$ More than $75 \%$ of children fatally or seriously injured in road traffic crashes are pedestrians or cyclists.

Socioeconomic gradients exist in children admitted with pedestrian and pedal cycle injuries, ${ }^{2}$ but little is known about trends in these gradients over time. We examined trends in admission rates and socioeconomic gradients for traffic injuries in children between 1992 and 1997.

\section{Participants, methods, and results}

We considered children aged 0-14 years who were admitted to hospital for pedal cycle, pedestrian, or other transport injuries in the 862 electoral wards in the old Trent NHS Executive Region, United Kingdom, between 1 April 1992 and 31 March 1997. An admission for fracture of a long bone needing an operation was a severe injury. ${ }^{3}$ We allocated each patient to their electoral ward using their postcode, aggregated the data at ward level for each year of the study, and calculated admission rates in each ward using population data.

We used random effects Poisson regression to find rate ratios for changes in admission rates and socioeconomic gradients over the study period. We categorised wards into fifths using the Townsend score for each ward. To assess whether the socioeconomic gradients had changed over the study period we conducted tests for interaction. Confounding variables were rurality, proportion of boys in the ward, proportion of black and Asian residents, and distance from the centre of the ward to the nearest acute hospital trust.

During the study period, admissions of children with severe injuries from road traffic crashes were 1061 pedal cyclists, 449 pedestrians, and 426 others. Admission rates for severe injuries among cyclists and pedestrians increased by $4.9 \%$ (95\% confidence interval $0.6 \%$ to $9.5 \%)$ and $9.8 \%(2.9 \%$ to $17.3 \%)$ each year (table 1$)$. Conversely, admission rates for other severe injuries decreased by $10.8 \%$ (4.6\% to $16.7 \%$ ) each year. Socioeconomic gradients did not change significantly during the study period.
Division of Primary Care, University of Nottingham, Nottingham NG7 2RD Carol Coupland senior lecturer in medical statistics Julia Hippisley-Cox senior lecturer in general practice Denise Kendrick senior lecturer in general practice Lindsay Groom research unit coordinator Elizabeth Cross researcher in general practice

Boki Savelyich researcher in general practice

Correspondence to: C Coupland carol.coupland@ nottingham.ac.uk

BMJ 2003;327:593-4 